\title{
Environmental effects and monitoring system design of energy cooperation between China and Russia in the context of "One Belt, One Road"
}

\author{
Jie $\mathrm{Gao}^{1}$ \\ ${ }^{1}$ School of Foreign Languages,Northeast Petroleum University, Daqing, China.
}

\begin{abstract}
In the context of the Belt and Road, China-Russia energy cooperation has become closer, and energy cooperation industries are distributed in various energy fields. This paper firstly proposes that environmental monitoring of energy cooperation industries has positive significance for energy cooperation in the context of the Belt and Road, then elaborates the current situation and environmental effects of SinoRussian energy cooperation, leads to the design of environmental effect monitoring system for energy cooperation industries, which is based on satellite and spectral estimation to analyze the changes of water and soil areas such as water and vegetation and the degree of atmospheric pollution, and derives the environmental benefits of industries. Finally, we conclude with a summary and outlook on the prospects and effects of SinoRussian energy cooperation.
\end{abstract}

\section{Introduce}

Russia, as one of the most important countries in China's "One Belt, One Road" strategy, is a very important pivot point. Therefore, strengthening the cooperation between the Russian and Chinese governments in the energy industry is in line with the political interests of both countries and the demands of their economic development, as well as the promotion of the economic development of both sides. It is good for the stability of the current economic situation in Asia and Europe and the world as a whole. In this paper, we analyze the situation of energy industry cooperation between China and Russia under the "One Belt, One Road" strategy proposed by China, and design an environmental monitoring system based on energy industry cooperation by analyzing the impact and effect of energy extraction, transportation, and use on the environment, and through this system, we promote the smooth development of energy industry cooperation between the two countries. ${ }^{[1]}$ This system will facilitate the smooth development of energy industry cooperation between the two countries, and develop corresponding environmental protection strategies and industrial standards for energy cooperation, promote energy security, make the cooperation develop in the direction of high quality, set a model for cooperation between countries in the region, and expand the influence of China's "One Belt, One Road".

\section{Current Situation and Environmental Effects of China-Russia Energy Cooperation}

\subsection{Current Situation of Russian-Chinese Natural Gas Energy Cooperation}

Chinese and Russian cooperation in natural gas is also in fact with the laying of natural gas pipelines. At the same time, Chinese domestic energy companies have invested in natural gas projects developed by Russia in the Arctic region. In 2015, Russia was hit by Western economic sanctions, which caused damage to the domestic economy and a significant devaluation of the currency, and put gas development projects on hold. At this time, China entered into cooperation agreements with domestic Russian gas development projects and purchased part of the project's equity. ${ }^{[2]}$ To date, China's stake in the Russian Arctic gas project has risen to nearly $30 \%$. This project is also the first natural gas trade between China and Russia since the "One Belt, One Road" economic strategy was introduced, which reflects the positive impact of the "One Belt, One Road" Silk Road on energy cooperation and strategic relations between China and Russia. The delivery of Russian natural gas will greatly alleviate China's domestic energy needs, improve energy reserves, and provide strategic energy security. And to a certain extent it will improve the environmental pollution in China. China's energy structure is shown in Figure 1. 


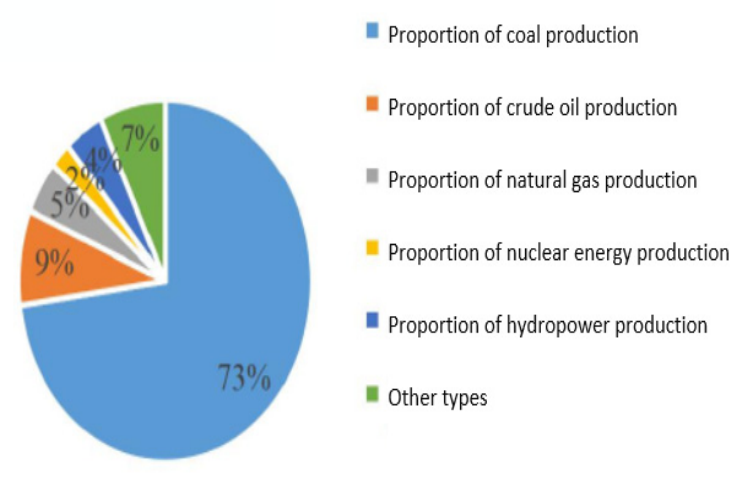

Fig.1 China's energy structure diagram

\subsection{Current status of Russian-Chinese power and energy cooperation}

In addition to the above-mentioned cooperation between China and Russia in the oil and gas energy industry, the electricity and coal industries are also important objects of cooperation between the two countries in the energy industry ${ }^{[3]}$. The cooperation between China and Russia in electric power industry cooperation has been laid out widely and for a long time, mainly through the sale and purchase of electric power, the construction of power generation equipment and the technology of power generation equipment to carry out this trade exchange and industrial cooperation. At present, the cooperation between the two countries is mainly focused on wind power generation, which has no impact on the environment. The largest wind power project in Russia is the Ulyanovsk wind power project, which is also a joint project between the two countries. The project was undertaken and assembled by China's Heilongjiang Thermal Power Company and is currently achieving good power transmission results. In addition, with the intention of cooperation between the two governments, power generation companies of both countries hope to develop hydroelectric power generation in the Russian Far East and Siberia, and promote development through the provision of appropriate sites and facilities. Yangtze River Hydropower Group has also signed a letter of intent with the Russian counterpart. At the same time, the Russian government has concentrated its main resources for hydroelectric power generation in the Far East, the Chinese counterpart of which is the northeastern region of China. The northeastern region is located close to the Far East and has a large population and a high demand for electricity. As China's old domestic industrial base, the northeast has a single energy structure, making the region's economic development at a backward level in the country. The cooperation agreement with Russia's Far East region for power transmission will enable the transfer of its hydroelectric power to the northeastern part of China, thus alleviating the environmental impact of the northeastern part of the country due to the burning of coal for power generation. In the future, hydroelectric power generation is likely to be a major focus of cooperation between China and Russia in the energy industry as a good project that does not pollute the environment and produces energy at the same time.

\subsection{Environmental effects of cooperation}

The impact of energy consumption on the environment is mainly manifested in the pollution of water, atmosphere, soil and biological vegetation. In particular, the polluting gases and pollutants released after energy consumption are easy to cause great damage to the environment and pose a threat to the production and life of human beings, which is also an urgent concern and a problem that needs to be solved by governments and people of all countries. For China, the coal-based energy consumption structure, including the consumption of other fossil energy sources, mainly causes a large amount of emissions of waste water, waste gas and waste residue, which easily causes damage to water, air and soil. The main pollution of coal-based energy consumption structure is the emission of harmful gases such as sulfur dioxide and waste residues from combustion, which are harmful to the environment. The impact of Sino-Russian oil and gas energy cooperation on China's environmental quality is in general an indirect one. The first thing that Russia and China can do through oil and gas energy cooperation is to change China's traditional coal energy-based energy consumption structure and start rational optimization of energy consumption. Secondly, when Russian oil and gas energy enter the Chinese energy consumption market, they can play a corresponding substitution role, replacing a part of coal energy consumption, which will correspondingly reduce a part of sulfur dioxide and other emissions and waste from coal combustion, thus contributing to the improvement of China's environmental quality. ${ }^{[4]}$

\section{Design of environmental effect monitoring system for energy cooperation industry}

\subsection{Monitoring the environmental effects of water and soil in the energy cooperation industry}

The main means of monitoring the soil and water environment is to extract the soil and water information from the original rivers and reservoirs through the remote sensing images of satellites, and to obtain the remote sensing images of the study area after the pre-processing of radiation calibration, atmospheric correction and band fusion, and then to calculate the area of the original rivers, reservoirs and green vegetation, which is used to assess the impact of the energy cooperative industry on the soil and water environment. ${ }^{[5]}$

The specific research method is based on satellite data, calculating the annual normalized difference vegetation index (NDVI) and annual normalized difference water body index (NDWI) for the years before and after the construction of the energy cooperative industry, inversion to obtain the vegetation cover and land use type data, and analyzing the impact of the industrial area on the vegetation growth and ecological environment through buffer zone analysis and spatial superposition analysis 
methods. The flow chart of the analysis is shown in Figure 2.

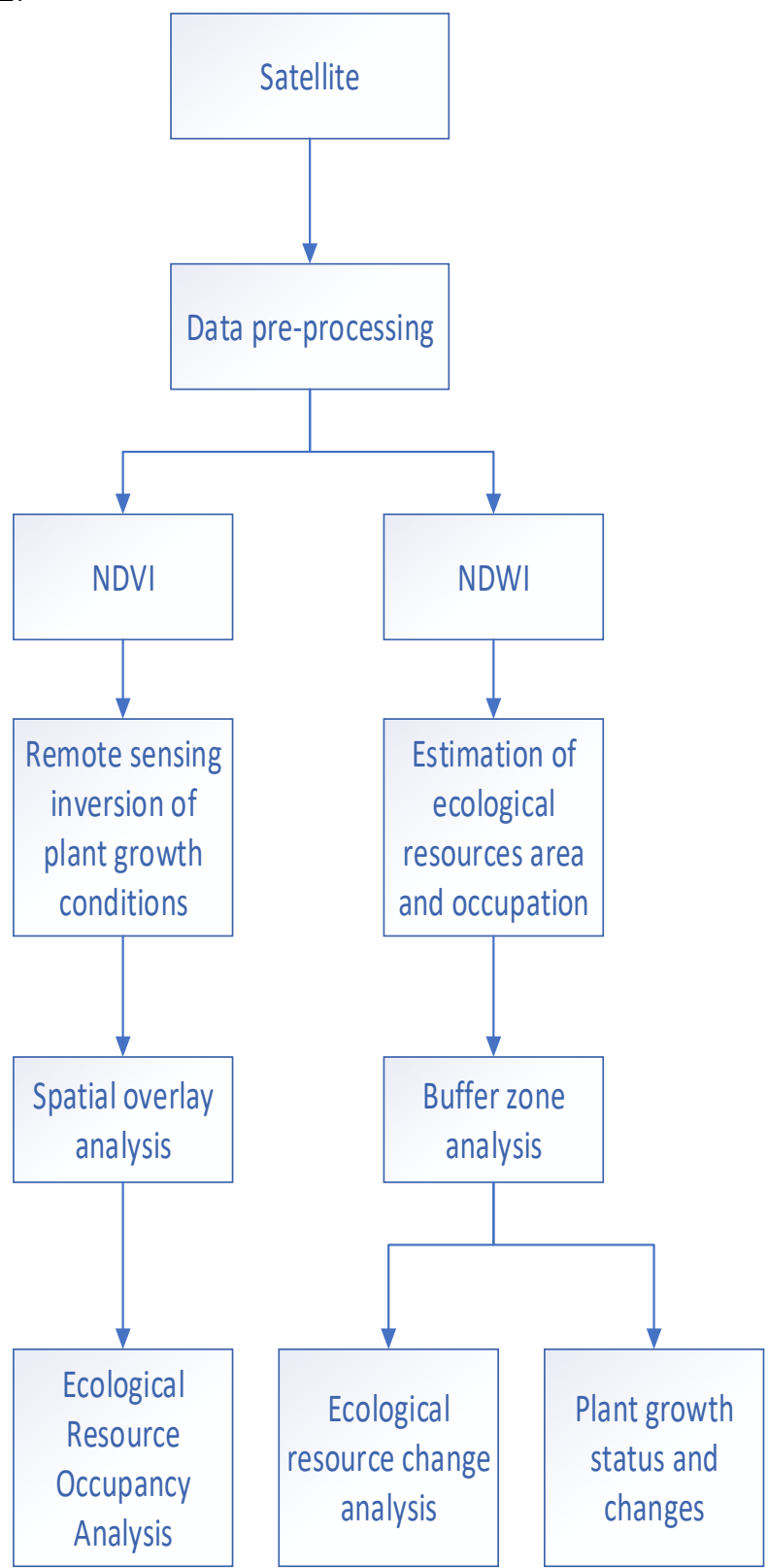

Fig.2 Flow chart of soil and water environment monitoring and analysis

The normalized differential water body index, calculated from the ratio of the difference between the apparent reflectance and the sum of the green light band and the near-infrared band, mainly takes advantage of the strong absorption of water bodies in the near-infrared band and the strong reflectance of vegetation to extract the water body information in the image by suppressing the vegetation and highlighting the water bodies, which has the feature of high accuracy of water body classification.

$$
N D W I=\frac{\rho_{\text {green }}-\rho_{\text {nir }}}{\rho_{\text {green }}+\rho_{\text {nir }}}
$$

In equation (1), $\rho_{\text {nir }}$ is the apparent reflectance in the near infrared; $\rho_{\text {green }}$ is the apparent reflectance in the green wavelength band. After extracting the range, the set of overlap places are manually trimmed in combination with visual interpretation to obtain the final water range. ${ }^{[6]}$

Surface vegetation plays a key role in ground-air energy exchange and the Earth's carbon and nitrogen water cycle, so it is closely related to the ecological environment. The vegetation cover is the percentage of the vertical projection of vegetation on the ground to the total area of the study area, which can effectively reflect the characteristics of surface vegetation distribution and monitor the ecological environment changes, and is an important parameter index in ecological environment evaluation. The NDVI is the best indicator of vegetation growth, biomass and vegetation cover dynamics, and is calculated from the ratio of the difference between the apparent reflectance and the sum of the red wavelengths.

$$
\begin{gathered}
N D V I=\frac{\rho_{\text {nir }}-\rho_{\text {ed }}}{\rho_{\text {nir }}+\rho_{\text {red }}} \\
F V I=\frac{N D V I-N D V I_{S}}{N D V I_{V}-N D V I_{S}}
\end{gathered}
$$

In equation(2), $\rho_{\text {nir }}$ is the apparent reflectance of NIR, and $\rho_{\text {red }}$ is the apparent reflectance of red light band; in equation (3), $N D V I_{s}$ and $N D V I_{v}$ represent the NDVI completely covered by soil and vegetation in the region, respectively, and the larger the $\mathrm{FVC}$, the more luxuriant the vegetation is and the better the ecological environment is.

\subsection{Atmospheric impact monitoring of the energy cooperative industry}

The main pollutants in the air are sulfur dioxide, nitrogen dioxide, and total suspended solids, and the use of differential absorption spectroscopy in the energy cooperative industry can effectively identify the type and concentration of pollutants and analyze the impact of the industry on the atmosphere.

Differential absorption spectroscopy by its nature is based on the absorption of light radiation by molecules. When a beam of light passes through the atmosphere, the light is selectively absorbed by the molecules in it, causing a change in the intensity and spectral structure of the light, and the absorption spectrum can be derived by comparing it with the spectrum of light emitted from a light source. By analyzing the absorption spectrum in a certain wavelength band, it is possible to determine not only the presence of certain components, but also the content of these substances and to obtain the concentration of the corresponding gas in the atmosphere. The absorption of light by substances is in accordance with the LambertBeer law.

$$
I(\lambda)=I_{0}(\lambda) \exp \left[-L_{\sigma}(\lambda) c\right]
$$

In equation (4), $\mathrm{I}(\lambda)$ is the detected light intensity; I_ $0(\lambda)$ is the light intensity of the light source; L is the light range length and $\mathrm{c}$ is the concentration; $\sigma$ is the absorption cross section, which indicates the absorption capacity of the substance. ${ }^{[7]}$

In actual atmospheric measurements, the extinction factors mainly include Rayliegh scattering, Mie scattering, and the influence of other substances in the atmosphere. When these effects are considered, equation (4) is expanded as

$$
\begin{aligned}
I(\lambda)= & I_{0}(\lambda) \exp \left\{-L\left[\sum_{1}\left(\sigma_{i}(\lambda) c_{1}\right)\right.\right. \\
& \left.\left.+\varepsilon_{R}(\lambda)+\varepsilon_{M}(\lambda)\right]\right\} A(\lambda)
\end{aligned}
$$

where, $A(\lambda)$ denotes the transmission function of the system. The change in optical thickness caused by 
Rayliegh scattering and Mie scattering varies slowly with wavelength, while the change in optical thickness caused by molecular absorption properties varies rapidly with wavelength. The spectral change caused by scattering is called "broadband" spectrum (low frequency part), and the spectral change caused by molecular absorption is called "narrowband" spectrum. The "narrow-band" spectrum, which varies rapidly with wavelength, can be separated out using a high-pass filter. The separated molecular absorption spectrum is fitted with a reference spectrum, and the concentration of light-absorbing substances in the atmosphere can be calculated. This is the analytical process of differential absorption spectrometry. The diagram of the atmospheric environment monitoring equipment based on differential absorption spectroscopy is shown in Figure 3.

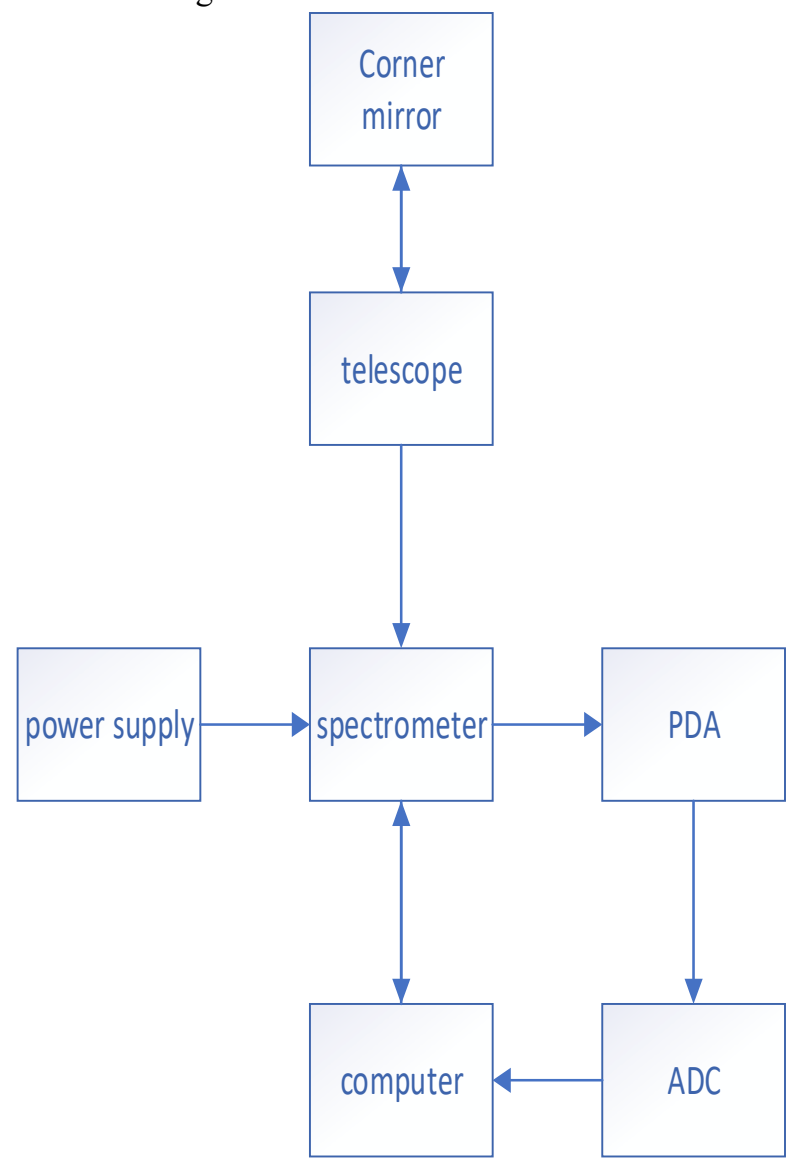

Fig.3 Atmospheric environment monitoring equipment diagram

\section{Conclusion}

In the context of "One Belt, One Road", based on theoretical and empirical analysis, it is concluded that the environmental impact of Sino-Russian oil and gas energy cooperation on China is positive. On the one hand, China's import of Russian oil and natural gas through SinoRussian oil and gas energy cooperation can replace part of the consumption of inefficient energy sources such as coal, which can improve China's energy utilization efficiency and reduce pollutant emissions, and thus improve China's environmental pollution situation. Therefore, as long as China's economic growth reaches a certain critical value, pollutant emissions will be continuously reduced, and thus
Sino-Russian oil and gas energy cooperation will reduce pollutant emissions after reaching a critical value when promoting China's economic growth, which will have a positive effect on China's environmental pollution control. By analyzing and monitoring the environmental impact effects of China-Russia energy cooperation industry, we can reasonably carry out industrial planning and guide the environmental management policy and strategy.

\section{Acknowledgments}

This paper is the result of the research project on the deep integration of Daqing into the construction of "One Belt and One Road" (No. DSGB2021069).

\section{References}

1. Mu Hang, He Chao, Ruan Qiuming, Wang Danlu, Zhou Xiaoyan, Yang Lu, Tu Peiyue, Wang Haiyang, Hong Song. Spatial and temporal distribution characteristics of PM (2.5) pollution and population exposure risk in countries along the "Belt and Road"[J/OL]. Journal of Environmental Science:112[2021-06-05]

2. Gong Wei, Li Li, Liu Qinhuo, Xin Xiaozhou, Peng Zhiqing, Wu Mingquan, Niu Zheng, Tian Haifeng. Remote sensing monitoring of ecological and environmental impacts of hydropower station projects in the "Belt and Road" region[J]. Journal of Geoinformation Science,2020,22(07):1424-1436.

3. BobrukIgor. Research on the influencing factors and countermeasures of Sino-Russian energy industry cooperation[D]. Xi'an University of Petroleum, 2020.

4. Yang Zhongshan, Wei Xiaoxue. Total Factor Energy Efficiency in Key Regions of "Belt and Road"Measurement, Decomposition and Analysis of Influencing Factors[J]. China Environmental Science,2018,38(11):4384-4392.

5. Ran H-L. Study of differential absorption spectral inversion method in environmental monitoring system $[\mathrm{J}]$. Science and Technology Perspectives,2016(17):216.

6. Xu Chengliang. Research on the impact of ChinaRussia oil and gas energy cooperation on the environmental effects in China [D]. Hubei University,2015.

7. Cui Houxin,Qi Rubin,Zhang Wenjun,Xu Kexin. Design of online continuous monitoring system for atmospheric quality by differential absorption spectrometry $[\mathrm{J}]$. 